\title{
Recirculating carbon dioxide refrigeration unit for freezing food
}

\author{
Evgeniy Neverov ${ }^{1}$, Igor Korotkiy ${ }^{1}$, and Ilya Prib $^{1, *}$ \\ ${ }^{1}$ Kemerovo State University, 6 Krasnaya Street, 650000 Kemerovo, Russia
}

\begin{abstract}
The article describes the development process of a refrigeration unit using carbon dioxide as a refrigerant. A feature of the plant is the possibility of recirculating carbon dioxide. The authors substantiate the use of the natural substance $\mathrm{CO} 2$ as a refrigerant and consider the prospects for using the refrigerant R744. The efficiency of the cycle of a one-stage subcritical refrigeration unit is analyzed. The authors have designed a recirculating carbon dioxide refrigeration unit based on the traditional subcritical cycle. The essential and auxiliary components of the refrigeration machine were presented and described. The developed scheme allows freezing food products by direct contact of the product with snow-like carbon dioxide. After that, the sublimation process takes place in the freezing chamber and the gas-liquid mixture is sent through the liquid separator for recirculation. The article describes the operation of the system diagram, the principle of operation, and the purpose of the elements of automation and regulation.
\end{abstract}

\section{Introduction}

Natural refrigerants are substances that occur naturally in nature. Unnatural or synthetic refrigerants are man-made chemicals that do not occur naturally. The correctness of the term "natural refrigerants" is sometimes controversial. People today distinguish between substances whose chemical properties and safety have been fully investigated, and these chlorine and fluorinated gases, the negative impact of which on the ozone layer leads to global warming and a threat to environmental safety. As a result, the scientific community is constantly discussing the problem of using these gases. [1] The most common natural refrigerants include ammonia (NH3, R717), carbon dioxide (CO2, R744), and hydrocarbons (HC) such as propane (R290), isobutane (R600a), and propylene (R1270) (known as propane).

In addition, mixtures of ammonia and dimethyl ether (R723) and various mixtures of hydrocarbons characterized by optimized operational and safety properties (isobutane and propane R441, etc.) are created.

Using $\mathrm{CO} 2$ as a refrigerant has expanded significantly in recent years. Using traditional refrigerants is restricted by various regulations and is more stringent around the world. Natural refrigerants are increasingly used [2].

\footnotetext{
*Corresponding author: prib_ilya123@mail.ru
} 
Carbon dioxide is used as an alternative refrigerant. Carbon dioxide is a type of natural gas that is environmentally friendly in terms of efficiency and safety as it is present in the Earth's atmosphere and biosphere. The advantage of $\mathrm{CO} 2$ is that it is harmless to the environment, neutral to the ozone layer, low cost, non-flammable, non-explosive, and compatible with mineral oil. To use $\mathrm{CO} 2$ as a refrigerant, you need to use water-cooled condensers and pipes with thicker walls than other refrigerants. Carbon dioxide is most commonly used in two-stage low temperature applications. The use of $\mathrm{CO} 2$ has been well shown in small refrigerators, domestic refrigerators, and heat pumps. $\mathrm{CO} 2$ is found in natural refrigerants like propane, butane, ammonia, water, each of which has own disadvantages. Propane and butane are flammable and explosive, ammonia is poisonous, water has a limited range of applications. Most of the essential and auxiliary equipment works with refrigerants such as ammonia and freon. Ammonia is used in large and mediumsized installations, while freon is more commonly used in medium-sized, small refrigerators, as it is less energy efficient. Synthetic freon has other disadvantages: ozone depletion, low efficiency and is not compatible with many oils. The transition to natural refrigerants is promising. Carbon dioxide has the following advantages: high refrigeration capacity, non-toxicity, and safety, not inertness regarding the material, low cost, and availability. Using $\mathrm{CO} 2$ is widely used in low temperature technology for its high efficiency and high refrigeration capacity. Figure 1 shows a comparison of the cooling capacity of $\mathrm{CO} 2, \mathrm{R} 22$, and $\mathrm{NH} 3$ where the advantage of carbon dioxide is clearly seen. [2]

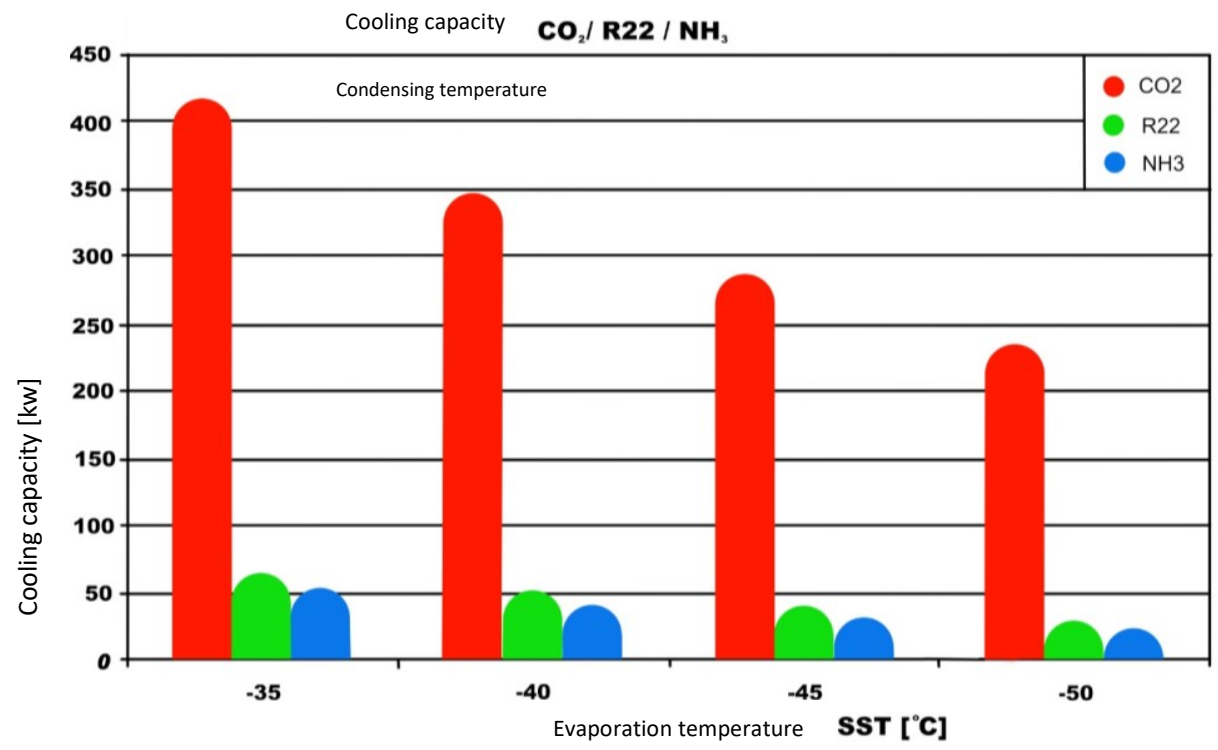

Fig. 1. Comparative graph of refrigerating capacity of refrigerants

The major disadvantages are high operating pressure up to $(10 \mathrm{MPa})$ and low critical temperature $\left(31^{\circ} \mathrm{C}\right)$. Carbon dioxide mixed with other refrigerants, propane and butane must eliminate these disadvantages. Because of its properties, carbon dioxide is becoming more and more popular as a refrigerant.

$\mathrm{CO} 2$ at atmospheric pressure is in the solid or gas phase. In the aggregate state of dry ice at a temperature $\left(-78.4^{\circ} \mathrm{C}\right)$. The triple point is reached at pressure $(0.52 \mathrm{MPa})$ and temperature $\left(-56.6^{\circ} \mathrm{C}\right)$, at this moment all three phases are in equal proportions. The critical point is reached when the temperature $\left(+31.1^{\circ} \mathrm{C}\right)$ is reached. At this moment, the densities of the liquid and gas phases are equal. It can also be used as a subcritical and supercritical refrigerant. [2] 


\section{Materials and methods}

This work develops a recirculating carbon dioxide refrigeration unit for freezing food products that allow freezing food products in an environment of gaseous carbon dioxide and recuperating it. In the first stage, we built the operation cycle of the installation in the P-h diagram (figure 2) and identified key points. Below, we will consider the cycle and the essential and auxiliary units, shut-off and control valves, and automation elements of the refrigeration unit.

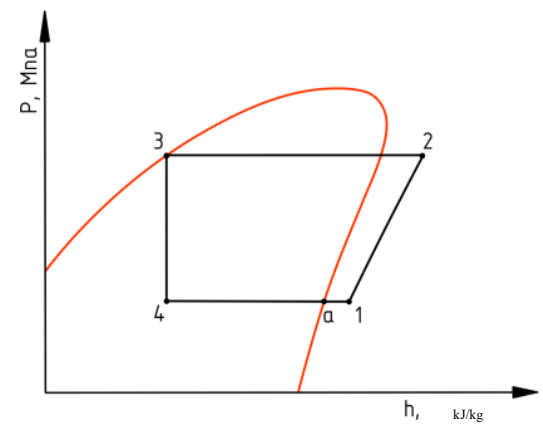

Fig. 2. Single stage subcritical refrigeration cycle.

Process a -1 overheating of a substance in a liquid separator

Process 1-2 gas compression in a compressor

Process 2-3 gas condensation in a shell-and-tube condenser

Process 3-4 throttling gas into the chamber

Figure 3 shows a scheme of a designed refrigeration unit. The recirculating carbon dioxide refrigeration unit for freezing food is composed of essential and auxiliary elements. 


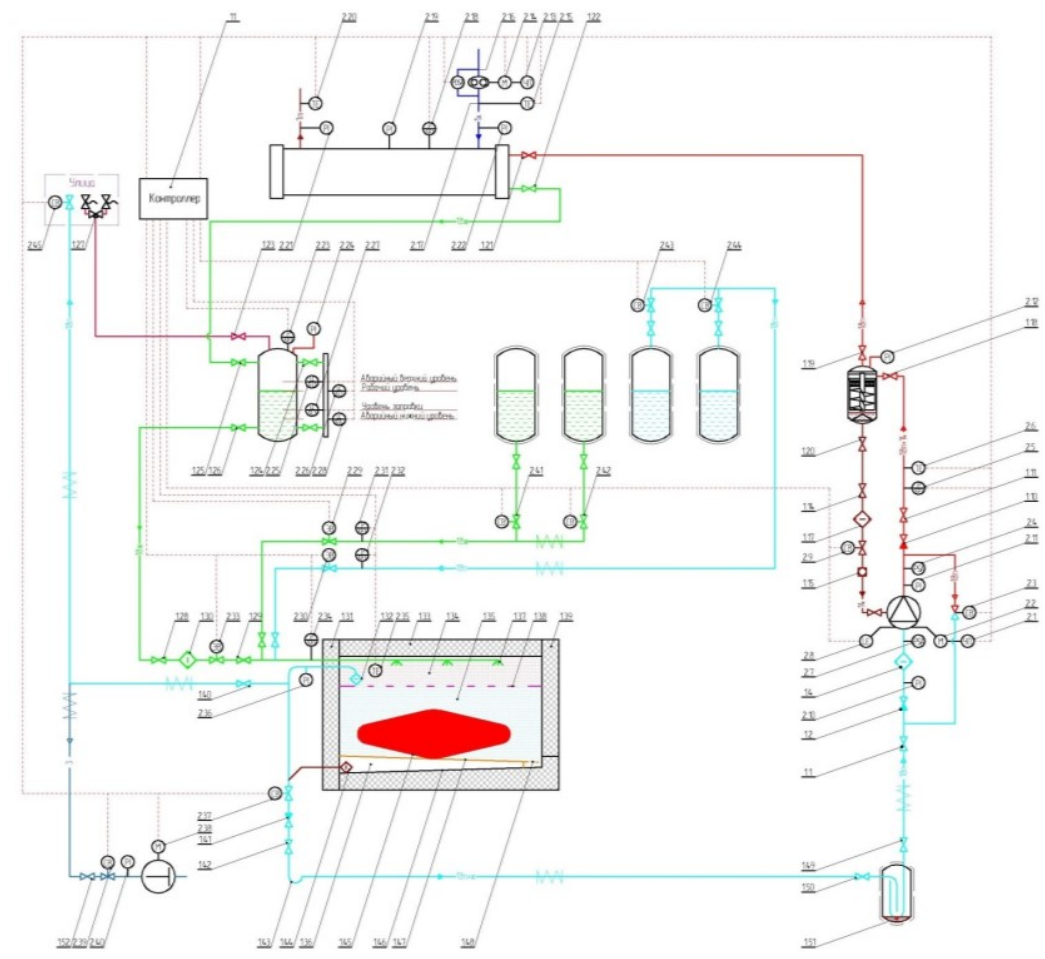

Fig. 3. Scheme of the designed refrigeration unit.

\section{Results and discussion}

The main units of the refrigeration machine include a compressor unit (1), an oil separator (2) of a cyclone type, a water-cooled condenser (3) of shell-and-tube design, a linear receiver (4), a cooling chamber (5), and a liquid separator (6).

The auxiliary elements of the installation are a cold water supply pump, a condenser (7), a vacuum pump (8), cylinders for supplying liquid carbon dioxide (9), and cylinders for supplying gaseous carbon dioxide (10), a controller (11).

Each of the essential and auxiliary components of the refrigeration machine includes auxiliary automation elements and valves.

The control and automation elements of the compressor unit (1) include a shut-off valve on the suction line (1.1), a check valve (1.2), a low pressure gauge (2.10) with a shut-off valve, a fine filter (1.4), a low pressure switch (2.7), compressor motor speed converter (2.1), solenoid valve (2.3), high pressure gauge (2.11) with shut-off valve, high pressure switch (2.4), check valve (1.10), discharge shut-off valve (1.11), sensor pressure (2.5), temperature sensor (2.6), oil shut-off valves (1.14), sight glass (1.15), solenoid valve (2.9), oil filter (1.17).

The unit for the functioning of the oil separator (2) includes a shut-off valve at the inlet to the apparatus (1.18), a valve at the outlet of the vessel (1.19), a high-pressure manometer (2.12), and a shut-off valve on the oil outlet line (1.20).

The water condenser automation kit (3) includes a temperature sensor (2.20) for a warm water circuit, a high pressure manometer (2.19) with a shut-off valve, a refrigerant pressure sensor (2.18), a water pump (7), a water pump differential pressure switch (2.16-2.17), a water pump motor shaft speed converter (2.13), a supply water temperature sensor (2.15), a 
gas line shut-off valve (1.21), a liquid line shut-off valve (1.22), pressure gauges for measuring incoming (2.22) and heated (2.21) water.

The operability of the linear receiver is maintained by a valve for connecting emergency pressure relief valves (1.23), a pressure sensor (2.23), a pressure gauge with a shut-off valve (2.24), valves for connecting a level and automation column (1.24), a filling level switch (2.27), an emergency lower liquid level (2.28), liquid refrigerant inlet valve from the condenser (1.25), liquid supply valve to consumers (1.26), upper alarm liquid level switch (2.25), operating level switch (2.26) and emergency pressure relief valves (1.27).

The elements of regulation, automation, and design of the refrigerated chamber (5) are valves on the liquid refrigerant supply line (1.28) and (1.29), filter drier (1.30), electronic expansion and control valve with a stepper motor (2.33), pressure sensor (2.34), removable chamber cover (1.31), coarse filter (1.32), temperature sensor (2.35), chamber body (1.33).

To describe the principle of operation of the refrigerating machine, the inner cavity of the refrigerated chamber is conventionally divided into three volumes: the upper volume (1.34), the middle volume (1.35), and the lower volume (1.36).

The refrigerated chamber assembly (5) includes nozzles (1.37), an upper partition (1.38), a chamber door (1.39), a valve for connecting a vacuum pump and a solenoid relief valve (1.40), a pressure gauge with a shut-off valve (2.36), a solenoid valve (2.37), nonreturn valve (1.41), suction shut-off valve (1.42), oil lifting loop (1.43), coarse filter (1.44), refrigerated product (1.45), lower floor surface of the chamber (1.46), lower partition (1.47), mesh opening (1.48), and the pressure relief solenoid valve (2.45).

The liquid separator (6) operates with the shut-off valves (1.49) and (1.50). An oil return hole (1.51) is provided at the bottom of the compressor suction pipe loop inside the vessel.

The vacuum pump (7) is connected to the refrigeration circuit through a shut-off valve (1.52), a solenoid valve (2.39), a pressure gauge with a shut-off valve (2.40).

The operation of the liquid carbon dioxide supply cylinders (9) is carried out using solenoid valves (2.41) and (2.42), as well as using an electronic expansion and control valve with a stepper motor (2.29) and a pressure sensor (2.31).

The carbon dioxide gas cylinders (10) work in tandem with the solenoid valves (2.43) and (2.44), the electronic expansion valve (2.30), and the pressure sensor (2.32). [8]

\section{Conclusion}

The technological development of the refrigeration industry in recent years allows the use of $\mathrm{CO} 2$ in both subcritical and transcritical refrigeration systems.

The article designed a recirculating carbon dioxide refrigeration plant based on a traditional subcritical cycle for freezing food. The circuit makes it possible to freeze food by direct contact with the food with snow-like carbon dioxide. After that, the sublimation process takes place in the freezing chamber and the gas-liquid mixture is sent through the liquid separator for recirculation. With the help of such a scheme and method of freezing, the refrigerating capacity increases, therefore, the heat transfer coefficient increases. All this allows to increase the shelf life of the product and reduce the time for its freezing, which means that the risk of bacteria formation is reduced.

The essential and auxiliary components of the refrigeration machine have been presented and described in a typical diagram. We have presented a description of the operation of the system diagram, the principle of operation, and the purpose of the elements of automation and regulation. 


\section{References}

1. On natural refrigerants, Survey information, Ozon Program, https://www.ozoneprogram.ru/

2. Refrigerant R744. A new breakthrough in air conditioning systems, Survey information, Laduga, Automotive engineering, http://laduga.ru/blog/r744/, free.

3. E. N. Neverov, I. A. Korotkiy, A. N. Rasshchepkin, M. I. Ibragimov, A. N. Grinyuk, IOP Conference Series: Earth and Environmental Science. International Conference on Production and Processing of Agricultural Raw Materials, 072022 (2021)

4. E. N. Neverov, I. A. Korotkiy, P. S. Korotkih, R. U. Skhaplok, I. A. Prib, IOP Conference Series: Earth and Environmental Science. Cep. "International Science and Technology Conference "Earth Science"" , 012042 (2021)

5. E. N. Neverov, I. A. Korotkiy, L. V. Lifentseva, A. N. Rasshchepkin, Proceedings of Nizhnevolzskiy Agrouniversity complex: Science and Higher vocational education, 1(61), 326-337 (2021)

6. E. N. Neverov, I. A. Korotkiy, E. V. Korotkaya, A. N. Rasshchepkin, Periodico Tche Quimica, 18(37), 1-12 (2021)

7. E. N. Neverov, I. A. Korotkiy, P. S. Korotkih, L. V. Lifenceva, IOP Conference Series: Earth and Environmental Science. Current Problems and Solutions, 012039 (2019)

8. I. A. Prib, I National Conference -Kuzbass: Refrigeration Engineering and Biotechnology - 2019, 641-664, 182-185 (2019) 